\title{
Message from the Editor-in-Chief
}

\author{
Soji Ozawa
}

Published online: 26 May 2012

(C) The Japan Esophageal Society and Springer 2012

It is my great pleasure and honor to be appointed and to take over the role of the Editor-in-Chief of Esophagus. Since the publication of the first issue of Esophagus in 2003, 8 years have passed. We sincerely appreciate the cooperation of the former Editor-in-Chief, the associate editors, the members of the Editorial Board, the members of the International Advisory Board, the statistical consultant, the many authors, and the many readers who have created the present Esophagus.

During the past 8 years, authors from 19 countries in Asia, Oceania, North America, South America, Europe, and Africa have submitted manuscripts to Esophagus. Thus, Esophagus has gradually come to be recognized internationally. Since the adoption of an electronic manager system in 2009, the mean duration between the submission of a manuscript and the judgment of its acceptance for publication has decreased, reaching 107.9 days in 2011. The latest review system has contributed to the promptness of the responses to the authors.

The rate of acceptance is $41.4 \%$ for original articles and $67.6 \%$ for case reports. Original articles are welcomed so as to make Esophagus a high-quality journal. Case reports are also welcomed, as far as space permits, because rare cases of esophageal diseases are worthy of publication.

As far as special articles are concerned, Esophagus has reported the Japanese Classification of Esophageal Cancer, the Guidelines for the Diagnosis and Treatment of Carcinoma of the Esophagus, and the Comprehensive Registry of Esophageal Cancer in Japan, 1988-2003. These articles have played an important role in the distribution of scientific information from Japan to the entire world.

Scientists who are interested in esophagology, although few in number, are specialized in widespread areas such as epidemiology, anatomy, physiology, pathology, biochemistry, molecular biology, oncology, gastroenterology, surgery, endoscopy, and radiology. Esophagus is a special journal that is limited to esophagology but is suitable for the publication of the special activities of all the abovementioned scientists. Moreover, it is our desire that more new scientists will acquire an interest in esophagology through reading Esophagus and/or contributing to Esophagus.

Fortunately, Esophagus will be provided with an impact factor this year. We would like to make every effort to insure that Esophagus is indexed and included in the MEDLINE database in the near future.

\section{Soji Ozawa, MD, PhD, FACS \\ Editor-in-Chief \\ Esophagus}

S. Ozawa $(\square)$

Department of Gastroenterological Surgery,

Tokai University School of Medicine, 143 Shimokasuya,

Isehara, Kanagawa 259-1193, Japan

e-mail: sozawa@tokai.ac.jp 